\title{
Reading Difficulty Dynamics and Interventions Within Community Schools in Ghana; Evidence From Banka Community Senior High School Using the OARP Protocol
}

\author{
Simon Victory Quarcson Hamenoo ( $\sim$ simonvq5@gmail.com ) \\ Kwame Nkrumah University of Science and Technology \\ Rudith King \\ Kwame Nkrumah University of Science and Technology \\ Theresa Yaaba Baah-Ennumh \\ Kwame Nkrumah University of Science and Technology College of Science \\ Jennifer Dokbila Mengba \\ Kwame Nkrumah University of Science and Technology College of Science \\ Stephen Boadi Gyamfi \\ Ghana Education Service
}

\section{Research Article}

Keywords: Reading difficulty, Dynamics, Intervention, Protocols, Text recognition accuracy, and Text pronunciation accuracy

Posted Date: December 14th, 2021

DOI: https://doi.org/10.21203/rs.3.rs-1106757/v1

License: (c) (i) This work is licensed under a Creative Commons Attribution 4.0 International License. Read Full License 


\section{Abstract}

This study was designed to assess reading difficulty dynamics and develop the corresponding interventions for students in the Banka Community Senior High School within the Asante Akyem South Municipality of Ghana. The study used multiple research designs and research methods in soliciting data for the analysis. Both semi-structured questionnaires and interview guides were used for data collection. A 100-worded paragraph was taken from the introductory page of the Integrated Science Textbook for Senior High Schools to assess the reading difficulty of students using the One-Minute Administration of Reading Passages (OARP) protocol. Three sessions of readings were done; the first without intervention, and the subsequent readings with teacher interventions. The results of the study show that majority of the respondents had text recognition accuracy (TRA), text pronunciation accuracy (TPA) and reading speed (RS) problems. Thus, TRA, TPA, and RS scores were below the $80 \%$ benchmark in the first reading (without intervention). Nevertheless, TRA, TPA, and RS scores increased above the $80 \%$ benchmark for the second and third readings (with teacher interventions). Four causative factors for the reading difficulties (RDs), three locational dynamics, four durational dynamics, four reading frequency dynamics and four periodic dynamics of RDs were identified. The study concludes that RD reduces with teacher interventions. The findings of this study is not a generalization of reading difficulty dynamics and intervention in all community schools in Ghana but rather presents contributions to an emerging academic problem which could have implications on SDG 4 in the near future within community schools. Hence, the need for setting up reading clubs in community schools towards reducing reading difficulties among students.

\section{Introduction}

Throughout educational literature, knowledge exists on the subject of reading difficulty and the dynamics of reading within the educational system from the basic to the tertiary level. Nevertheless, there seemed to be a lack of current interest in the subject. The lack of current and up-to-date research on the subject seemed to create a missing link on the current trends of the phenomenon of reading difficulty dynamics and interventions among Senior High Schools. There also appeared to be a lack of evidence-based reading intervention programs for struggling readers in the Senior High Schools in Ghana particularly Community Schools which are classified as 'less endowed' by the Ghana Education Service (GES). Whilst several factors account for the reading difficulties among students, there seemed to be no information on the phenomena in communities schools in Ghana. These gaps thus become important for this research upon which corresponding reading interventions are developed.

According to Bettinger and Long (2009), many students struggle with the literacy skills needed to be successful in higher education. The difficulties emerge within students' capabilities in reading and writing (Gruenbaum, 2012). Studies (Swanson et al., 2009; Vaughn et al., 2012) have shown that students with significant learning difficulties have underlying neurological or information-processing disorders. Also, many students with significant reading difficulties demonstrate poor working memory (Cain, 2004; Wawryk-Epp et al., 2004), which interferes with understanding the sentences they read (Swanson \& O'Connor, 2009; Vaughn et al., 2012). Whilst reading is a complex process that is crucial to students' academic success (Neumann et al., 2008), reading difficulty is the inability to quickly and accurately read text with appropriate expression within a reasonable time (Huang \& Luo, 2011; Luo, 2013). At the heart of the teaching and learning process is the act of reading because reading facilitates teaching and learning and must also involve an interaction between thought and language (Reading Comprehension: Theory and Practice, 2000).

Research thus supports the importance of engaging students in activities that promote reading along with decoding skills (Neumann et al., 2008; Therrien et al., 2006). Teachers, therefore, need efficient means of assessing their students' reading difficulties through appropriate interventions. Previous studies (Chard et al., 2002; Alber-Morgan et al., 2007) have also shown that students who struggle with fluency avoid reading activities, and also have problems with word recognition, text pronunciation, reading speed, and reading motivation. Invariably, when students' learning needs are not met, gaps in reading widen as struggling readers lose confidence (Fuchs et al., 2001). Consensus also exists among scholars, educationists, professionals, and parents that literacy (ability to read and write) is essential for students' progress. Literacy as defined by 
Aitchison and Alidou in the 2009 United Nations Educational, Social and Cultural Organisation (UNESCO) report is the percentage of the population aged 15 and above who can, with understanding, read and write a short, simple statement on their everyday life. Nevertheless, educators and students face many challenges in implementing and practicing effective reading (Neumann et al., 2008). UNESCO (2009) statistics for instance show that the literacy rate in Ghana for adults stood at $67.2 \%$ and $80.8 \%$ for the youth aged $15-24$ years. The adult literacy rate in Ghana further increased from $67.2 \%$ in 2010 to $76.6 \%$ as at 2015 according to a World Data Atlas (2019). Amidst this promising progress which was largely due to multiple governmental and international interventions such as school feeding programme, eradication of schools under trees, provision of community schools, cost absorption policies, there still exist reading difficulties in community schools in Ghana not excluding Banka Community School within the Asante Akyem South Municipality.

Teachers therefore, have duties to develop students' reading skills and abilities (Gruenbaum, 2012) as reading difficulties pose academic challenges to students at all levels (Ambe, 2007). The Ghana Library Authority has also noted with concern the declining rate of library patronage and minimal reading materials, and has therefore declared 2019 as a 'year of reading' and has provided 15 new libraries and books for the country's growing population (Ghana Library Authority, 2019). This study is therefore important because it is the first scientific study on the Banka Community School. The findings thus serve as baseline evidence on reading difficulty dynamics and interventions in the school thereby providing a premise for developing future interventional programs for addressing reading difficulties in Community Schools in Ghana. What is further important is that the respondents of this study were the pioneer students of the Banka Community Senior High School for the 2019 West African Examination Council (WAEC) exams. Their reading abilities thus become important for the outcome of the WAEC exams.

\section{Factors And Dynamics Of Reading Difficulties}

\section{Factors Influencing Reading Difficulties}

Factors influencing reading difficulty can be internal, external, biological or genetic.

\section{Internal Factors}

Internal factors emanate from the students' emotional and psychological faculties. Paramount among the internal factors is students' motivation to read (Sani et al., 2011; Peterson et al., 2000; Sanford, 2015), students' reading interest (Issa et al., 2012) and lack of self-confidence coupled with low motivation for learning and anxiety (Peterson et al., 2000). Guthrie and Wigfield (2000) in their study for instance notes that as students move through the grades, their motivation to read tends to decline. Acheaw \& Larson (2014) in their study of 1000 Polytechnic Students in Ghana have found that reading is boring to $56 \%$ of the students.

\section{External/ Environmental Factors}

External factors constitute the student's environment which includes the home and school. Issa et al., (2012) argues that students' home environments which consist of parental influence, parental involvement, and environmental influence have positive effects on students' academic success. It means that students' environments have an influence on establishing good reading habits. The external factors also include teaching methods, an adequate number of teachers and school facilities (Issa et al., 2012). The use of good teaching methods that are directed to improve reading skills is important for students' motivation in reading.

\section{Biological and Genetic Factors}


Research also suggests that reading difficulties are caused by the interaction between genetic and environmental factors which will produce a higher or lower risk of having dyslexia (Snowling, et al., 2004), a condition "involving difficulty in learning to read or interpret words, letters and other symbols" (Oxford Dictionary, $10^{\text {th }}$ ed p. 322). For instance, ailments, sicknesses, diseases, disabilities, deformities, and tumors have been known to have contained biologically restraining factors on effective reading among different age groups. Genetically, research further suggests that reading disorders do run in families, so parents with reading disorders are likely to have children with reading disorders (Lagae, 2008) and that there is about $50 \%$ chance of a boy having reading difficulty if his father has a reading disability and about $40 \%$ if his mother has a reading disorder. In fact, the genetics of reading disorders have been studied for the past 25 years and different studies have linked different genes to reading difficulty (Harlaar, et al., 2007; Snowling et al., 2004) which are related to brain development. In another study, Friend et al., (2008), have found that genetic influences were higher than environmental influences among children whose parents had a high level of education, compared with children whose parents had a lower level of education.

\section{Dynamics of Reading Difficulties}

There are different dynamics for reading. Reading can be for leisure, academic, research, assignment, or a project. In this study, reading is restrained to academic purposes. Academic reading involves the reading of lecture notes, textbooks for research, and examination purposes. Academic reading involves an efficient, active, interactive, and critical reading of materials (Manning, 1997). Studies show that academic reading requires both deep and surface approaches for better comprehension (Booth, 2003; University of Southampton, 2003). In the study by Singh (2011) on a hundred (100) higher secondary students randomly selected from two higher secondary schools, the results indicate that girls and boys differ significantly in their reading habits and academic achievements. Reading frequency and dynamics can include reading daily, weekly or monthly regularly or irregularly; and at different durations ranging from less than one hour, at most one hour or more than one hour or without any durations. The application of these reading dynamics differs among individuals and groups which can be constrained or influenced by the causative factor(s) of reading difficulties. Conventionally, reading can be done in-school or out-of-school settings. Reading difficulties can emanate from text recognition, text punctuation, reading speed problems among others.

\section{Reading Difficulty Interventions and Strategies}

To improve the reading proficiency of students who struggle with reading, there is the need for intensive, systematic, and explicit instruction in addition to regular classroom reading instruction (Texas Education Agency, 2001; Gruenbaum, 2012). It is important to recognize that interventions and activities must be chosen carefully based on students' reading difficulties and needs. To determine a student's independent reading difficulty, the teacher needs to asks the students to read two or three previously unread passages from a grade-level text with similar levels of difficulty and readability (Texas Education Agency, 2001) and then periodically assess the reading difficulty of the students. Interventions shown to be successful in helping students gain fluency are assisted, repeated, group/paired readings, readers' theatre, corrective feedback, among others (Texas Education Agency, 2001; Wawryk-Epp et al., 2004; Mathes \& Fuchs, 1994; Neumann et al., 2008; Peterson et al., 2000). Other studies (Research-Based Interventions Strategies on Reading, 2000; Texas Education Agency in 2001; WawrykEpp et al., 2004) also prescribed a number of strategies to overcome reading difficulties.

\section{The One-Minute Administration of Reading Passages (OARP) Protocol}

The OARP protocol was developed by the Texas Center for Reading and Language Arts and Texas Education Agency (1998). It involves reading by the students and crosschecking by the teacher for scoring. 
The strategies for this intervention include;

- Letting a student to read unnumbered copy of selected passages aloud as the teacher uses the stopwatch to time the student. If the student fails to say the first word of the passage after three seconds, the teacher tells the word and marks it as incorrect. The number of words is one hundred making the scoring over a hundred.

\section{Page Races and Repeated reading Intervention}

This intervention is to enable students to read quickly and accurately (Texas Education Agency, 2001). The strategies for this intervention include;

- Giving each student a copy of the reading material to read.

- Asking the student to read the passage two more times to increase speed and accuracy in reading the text and record the time after each reading.

\section{Phonological Awareness Intervention}

This intervention will enable students to read independently, with speed, accuracy, and expression, as they listen to a recording of a text being read fluently. Phonological Awareness refers to students' awareness of the sounds in words (Texas Education Agency, 2001).

The strategies for this intervention include;

1. Giving students a copy of the book to read along with the reader or the tape as they listen.

\section{Word Recognition Accuracy Intervention}

This intervention requires having a student read a passage then count the number of words correctly recognized divided by the total words read in the passage. The result can be multiplied by 100 to obtain the percent of word recognition accuracy (Wawryk-Epp et al., 2004).

\section{Choral Reading Intervention}

Choral reading requires repeated readings of a particular passage and students may read individual lines or stanzas alone, in groups, or unison but then, the teacher first reads to help set the pace (Research-Based Interventions Strategies on Reading, 2000).

\section{Assisted Reading Intervention}

This intervention also requires the teacher and the student to sit in a quiet location without any distractions with two copies of the reading material and the teacher instructs the student to begin reading out loud. If the student mispronounces a word or hesitates for longer than 5 seconds, the teacher tells the student the word, have the student repeat the word correctly and the student is directed to continue reading aloud through the passage (Research-Based Interventions Strategies on Reading, 2000). This intervention can be either in pairs or in groups. 


\section{Theoretical Underpinning and Justification for the study}

This research makes use of multiple theories to underline the study. These include the Componential model which describes how word recognition and knowledge influence the reading ability rather than the reading process (Reading Comprehension: Theory and Practice, 2000); the Skills Model which is traditionally concerned with reading through the teaching of reading comprehension skills. The skills model is adopted because the authors believe that effective reading is a skill that has to be taught and practised as evidence-based interventions are developed. Psycholinguistic Theory asserts that reading is a process of predicting meaning based on the reader's knowledge of oral language syntax, semantics, and phonological indications (Sheridan, 1981). This theory is applied in the study as text pronunciation and text recognition, and phonological indications were explored in the reading process of the respondents.

\section{Empirical Background on Reading Difficulty Dynamics and Interventions}

In a study by Neugebauer (2013), a new methodology for examining the potentially dynamic nature of reading motivation among students using a daily diary approach was explored. The study captured 119 fifth graders' daily in school and outsideof-school reading motivations. Data were analyzed using the multilevel model for change framework. Results indicate that students exhibited large daily intra-individual fluctuations in their levels of reading motivation within and between contexts. Neugebauer (2013)'s study and the present study support the dynamic assessments of reading difficulty dimensions and the corresponding causative factors. Two studies also included more than 130 students from four schools in Texas found that Enhanced Proactive Reading (EPR) had potentially positive effects on reading achievement (Research-Based Programs on English Mathematics and Science in Schools, 2012).

In related research aimed at improving the reading comprehension, 134 first-year college students of science, engineering, and liberal arts were sampled from developed/ developing provinces. The research went through two stages, with the first stage focused on improvement by skills-based teaching, but not with much improvement. At the second stage after deep analysis, it achieved a good improvement of reading ability with the result showing a significant difference, compared with that of the first stage (Luo, 2013). In an earlier study by Neumann et al., (2008), where 18 students were sampled for a reading survey of six positively phrased statements using a Likert scale, it was found that students' unison of reading at the choral reading was difficult due to their reading difficulties. During a paired reading, however, students' performance and unison were high.

Alber-Morgan et al., (2007) also argues that students who struggle with fluency avoid reading activities, and have problems with word recognition, comprehension, and motivation (Chard et al., 2002). When readers' ability to accurately comprehend text is impaired because they lack effective fluency, the readers often choose not to participate in reading behaviours such as making words, identifying words in texts, and writing words (Therrien et al., 2006). Rasinski (2004) also notes that the emphasis on fast reading has a negative impact on comprehension. Teachers need efficient means of assessing their students' reading difficulties, and teachers should use assessment results to implement appropriate interventions. Progress monitoring of student performance is a vital component of education so that if an instruction method is not working with a particular student, the program can be altered to fit the needs of that student (Fuchs et al., 1996).

\section{Conceptualization of the Study}

The study was designed to assess reading difficulty dynamics and intervention among Form Three students of the Banka Community School. The paper identified four mainstream factors (internal, external, biological, and genetic) that influence reading difficulty $(\mathrm{RD})$ within and outside the school environments. RDs which could be measured by text recognition, text pronunciation, reading speed, reading accuracy, reading frequency, vocabulary use, phonetics among others. The underlining theoretical basis of the study is situated within the componential model, skills model, and psycholinguistic theory. The interventions necessary to solving reading difficulty problems within the context of this research include repeated reading, phonological awareness, OARP protocol, choral reading, paired reading, and assisted reading (Figure 1). It is premised on this conceptual framework that the methodology of the study was developed leading to the findings of this study. 


\section{Study Site Description}

The study was conducted in the Asante Akyem South Municipality in a community called Banka. Fieldwork was conducted from January to March 2019. The Municipality is one of the 254 Metropolitan, Municipal and District Assemblies (MMDAs) in Ghana, and forms part of the 43 of MMDAs in the Ashanti Region. With the capital as Juaso, it shares boundaries with the Asante Akim Central Municipal in the north, Asante Akim North District in the northwest, and the Bosome-Freho District in the southwest, all in Ashanti Region. There are a total of five (6) Senior High Schools in the Municipality namely Juaso SHS, Bompata SHS, Ofoase SHS, Banka Community SHS (Figure 2), Konongo Odumase SHS, and one (1) Vocational institute at Asankare (Government of Ghana, 2016). The Banka Community SHS was established in November 2016 by the Government of Ghana under the John Mahama Administration as one of the E-block community schools in the country with a wellfurnished library, science and computer labs.

\section{Methods}

\section{Participants}

The participants of the study were the maiden final year students of the Banka Community School. There were three main classes at the time of the study consisting of 3 General Arts 1 (3 G/A 1); 3 General Arts 2 (3 G/A 2); and 3 Home Economics (3 $H / E)$. The population for the Form Three classes was 121 students. Based on sample proportions, 21 students were sampled from the $3 \mathrm{G} / \mathrm{A} 1$ whilst 58 and 12 respondents from the $3 \mathrm{G} / \mathrm{A} 2$ and $3 \mathrm{H} / \mathrm{E}$ respectively, making a sample of 91 respondents. Thus, each student had an equal chance of being selected through the stratified random sampling approach given that a master list (class list) existed. Besides, four key informants (Assistant Headmaster academics and three Form Masters of the three classes) were selected using the homogenous and typical purposive sampling techniques (Foley, 2018).

\section{Materials}

The study made use of both semi-structured questionnaires and interview guides for data collection. The questionnaire which comprised of two sections was designed for the students, the primary respondents in this survey. The questionnaire was administered directly to 91 sampled student respondents in the school during break periods. Consequently, the wording of the questionnaire was kept simple for students' comprehension. The interview guides were used to solicit data from the key informants (KIs) on the research objectives. Both primary and secondary data were collected for the study. The primary data were collected through observations and recordings. The secondary data were collected from published works such as journals and books through internet searches. Smartphone stopwatches were used for data collection on students reading speed. Data collection was done from February to March 2019.

\section{Procedure}

In this study, cross-sectional design (one-time data collection) and mixed research design (incorporating both qualitative and quantitative approaches) were adopted. Also, multiple data collection methods and analysis techniques were employed in order to strengthen the research findings and conclusions as typical of case studies (Creswell, 2013).

From Table I, the respondents were randomly selected per class until the required respective sample sizes were reached. This was possible because of the availability of the class list. Thus, each student had an equal chance of being selected through the stratified random sampling approach. The three classes were stratified with different class populations but with homogenous characteristics. This was operationalized through the lottery method (picking without replacement) and the required number of students adequately selected from each class/stratum. 
The overall sample size was arrived at using a mathematical equation as follows:

$$
\mathrm{n}=\frac{\mathrm{N}}{1+\mathrm{N}(\alpha)^{2}}
$$

Where; $n$ is the sample size, $N$ is the sample frame (121) from the Form 3 classes as presented in Table I), ${ }^{\alpha}$ is the margin of error defined at 95 percent confidence level (0.05).

Thus,

$$
\mathrm{n}=\frac{121}{1+121(0.05)^{2}}=91
$$

Nevertheless, because the study was designed to collect data from three different classes in Form 3, a proportionate distribution of the sample size by class was thus applied (Table 1).

Table 1 Sampling Approach and Procedure

\begin{tabular}{|l|l|l|l|}
\hline Classes & Population & Sample proportion & Sample per class \\
\hline 3 G/A 1 & 28 & $28 \div 121 \times 91=21$ & 21 \\
\hline 3 G/A 2 & 77 & $77 \div 121 \times 91=58$ & 58 \\
\hline 3 H/E & 16 & $16 \div 121 \times 91=12$ & 12 \\
\hline Total & 121 & 91 & 91 \\
\hline Key Informants & 1 \\
\hline Assistant Headmaster & 3 \\
\hline Form Masters & $\mathbf{4}$ \\
\hline Total
\end{tabular}

Source: Authors' Construct 2019.

\section{Measurement and Data Analytical Protocols}

There were three readings for the measurement in the study (only $1^{\text {st }}$ reading was without teacher intervention). A 100-word passage was taken and modified from the introductory page of the "Integrated Science textbook" of the Ghana Association of Science Teachers (GAST), $1^{\text {st }}$ edition. Students were made to read the 100-worded paragraph (see Box 1) without teacher intervention to assess reading difficulties. Text Recognition Accuracy (TRA, a measure of how well a text is recognised), Text Pronunciation Accuracy (TPA, a measured of how well a text is pronounced) and Reading Speed (RS) (number of words read per minute) were assessed by using a 100-worded paragraph within the OARP protocol. The students were given various reading interventions and their progress measured in their second and third readings against the first readings.

A pilot test of the 100-worded paragraph (see box 1) was done by selecting 20 students from four different Senior High Schools (e.g. Ofoase Senior High, Juaso Senior High and Bosome Freho SHS) in Form Three in order to establish a benchmark value for reading difficulties vis-a'-vis Luo's (2013) classification. These results were then converted into percentages and a benchmark value of $80 \%$ was set as a positive reading indicator in this paper. Merging evidence from Luo (2013) and the results of the pilot study informed the pegging of reading speed as Fast (100 wpm), Moderate (80 wpm), Slow (60 wpm), Very slow ( $<60 \mathrm{wpm})$. The adoption and contextualization of the reading speed in this present study is important as Luo (2013) advocates for 100 wpm as recommended reading speed for less difficult texts. 
Box 1: The 100-worded paragraph using the OARP protocol

The Ghana Association of Science Teachers (GAST) is a professional Association which has, since 1989, collaborated with Macmillan Publishers Ltd in the UK and Unimax Publishers in Ghana, to produce science books for senior secondary schools in Ghana. There is no doubt that the Macmillan/GAST science textbooks have made tangible tremendous impact on teaching and learning in Ghana. The book covers the SHS syllabus in integrated science including the agricultural science composition. Teachers and students in SHSs, Teacher Training Colleges, and Universities will find the books very useful. Therefore, one is expected to use it industriously for the best results.

Source: Authors' Construct 2019.

\section{Data Analysis}

The SPSS software version 20 was used to analyse the quantitative data. Descriptive statistics including univariate analysis (frequencies, percentages), and bivariate analysis (Pearson Correlation, Chi-Square statistic, and linear regression estimations) were computed to establish relationships between variables of interest. Qualitative data and the subjective views of key informants were summarized, presented in quotations and discussed.

\section{Reliability and Validity}

Data collected from respondents through observations, questionnaires, and interview guides were triangulated in order to strengthen the findings of the study. A briefing session/ orientation were done for each class prior to data collection. In those sessions which lasted for 10-15 minutes, the purpose of the study was explained to the students with the measurement methods, techniques and instruments. This was to ensure ethical considerations, data validity and limit measurement errors.

\section{Results}

\section{Causes of Reading Difficulties of Students}

Figure 3 shows about $35 \%(n=91)$ of the total number of respondents cited external factors as causes for their reading difficulties. About $33 \%(n=91)$ of the respondents also cited biological factors as causes of their reading difficulties. Students whose reading difficulties were due to internal factors represented $28 \%(n=91)$. Limited evidence $(4 \%, n=91)$ on the genetic factors contributing to students' reading difficulties also exist. This is made up disabilities/deformations (2\%), retardations, and eye problems (2\%) (Table 2). The internal factors include lack of interest (14\%) and no motivation (7\%), school-phobia (2\%) and can't speak good English (5\%). External factors thus include hunger (4\%), fear of making mistakes in class (15\%), farming chores (12\%), and poor basic education (4\%). The study also found strong evidence of sicknesses/diseases (20\%) and weaknesses (13\%) as contributing factors of biological causes of RDs.

Table 2 Identified causes of reading difficulties 


\begin{tabular}{llcc}
\hline & & Frequency & Percent \\
\hline Internal factors & Lack interest & 13 & 14 \\
& Lack motivation & 6 & 7 \\
& Doesn't like school & 2 & 2 \\
& Can't speak good English & 5 & 5 \\
External factors & Hunger & 4 & 4 \\
& Fear of making mistake in class & 14 & 15 \\
& Farming chores & 11 & 12 \\
& Poor basic education & 4 & 4 \\
Giological factors & Sicknesses/Diseases & 18 & 20 \\
& Weaknesses & 11 & 13 \\
& Disabilities/Deformations & 1 & 2 \\
& Asthmatic retardations & 1 & 1 \\
& Eye defects & 1 & 1 \\
\hline
\end{tabular}

Source: Fieldwork, 2019

An interview account with the Form masters of the school on the causes of students reading difficulties reveals that;

"Most of the students did not have a strong basic educational foundation before enrolment into the school. This is a farming community and most of the students would be helping on the farms for their parents and landlord/landladies. This could also limit their time to study and read books as they may come back tired from the farms. Some of the girls too are lazy and have their minds set on marriage. Nevertheless, when they are assisted they can do better". [Interview account, February, 2019]

\section{Assessment of Reading Difficulties and Interventions of Students}

Results of the study show a general progress in TRA and TPA values from the first readings (without intervention) to subsequent readings (with interventions). The mean values for TRA rose from 40.8 to 72.8. A similar trend is established for the TPA mean values which rose from 52.6 to 77.4. There is also a general increasing trend in the minimum TRA values from 3.0 to 16.0 for the $1^{\text {st }}$ reading without intervention to the $3^{\text {rd }}$ reading with intervention respectively. Similar observation is made for the maximum values as could be seen in Table 3. The general impression from the results is that text recognition and text pronunciations accuracies of the students increase with teacher interventions.

Table 3 Descriptive statistics on Reading Difficulties

\begin{tabular}{lccccc}
\hline & $\mathbf{N}$ & Range & Minimum & Maximum & Mean \\
& & & & & \\
\hline 1st reading.TRA* & 91 & 64.0 & 3.0 & 67.0 & 40.769 \\
2nd reading.TRA** & 91 & 88.0 & 12.0 & 100.0 & 56.352 \\
3rd reading.TRA** & 91 & 84.0 & 16.0 & 100.0 & 72.824 \\
1st reading.TPA* & 91 & 66.0 & 20.0 & 86.0 & 52.604 \\
2nd reading.TPA** & 91 & 68.0 & 32.0 & 100.0 & 70.945 \\
3rd reading.TPA** & 91 & 60.0 & 40.0 & 100.0 & 77.352 \\
Valid N (listwise) & $\mathbf{9 1}$ & & & & \\
\hline
\end{tabular}

* without teacher intervention

** with teacher intervention 
The results further show that majority of the respondents had text recognition accuracy problems using the OARP protocol. The text recognition problems were identified in the first reading and were used as a basis for developing corresponding interventions in the subsequent readings. The first reading (without intervention) showed that majority of the respondents had text recognition problems as a proxy for measuring reading difficulties. Thus, all respondents had less than $50 \%$ TRA scores out of the 100-worded paragraph as seen in the first curve and thus fall below the $80 \%$ benchmark which was set as a positive reading indicator (Figure 4). The second and third readings were respectively done after teacher interventions (the teacher does repeated reading of the paragraph to the respondents and makes all the necessary corrections). The second reading had seen improvements in TRA scores but majority of the students had TRA scores below the $80 \%$ benchmark. The third reading after teacher intervention shows much progress in the TRA scores as about $50 \%(n=91)$ of the respondents had TRA scores above the $80 \%$ benchmark within the OARP protocol.

An $\mathrm{R}^{2}$ value (a statistical measure of fit that indicates how much variation of a dependent variable is explained or predicted by the independent variable(s) in a linear regression model) has been estimated after the third reading (with intervention). The interventions were the teacher's repeated reading of the 100-worded paragraph using TRA, TPA, and RS for the respondents to hear. Students were also guided to read the 100-worded paragraph on their own for the second session after the teacher's intervention. Students were then made to do the third reading after the teacher's intervention. The prediction result shows that about $91 \%$ of variations in text recognition were attributable to teacher timely interventions (Figure 4). Nevertheless, the remaining $9 \%$ of the variations in TRA could not be explained and may be due to other variables such as internal, external, biological, or genetic factors influencing the reading difficulties.

Text Pronunciation Accuracy (TPA) for the students also followed a similar trend as with TRA. It shows that majority of students had text pronunciation accuracy problems in the first reading. All the students had TPA scores below the $80 \%$ benchmark for the reading without intervention. Nevertheless, TPA scores increased for the second reading and the third reading. There was a general improvement in TPA scores for the third reading with teacher intervention such that about half the number of students appeared to have TPA scores above the $80 \%$ benchmark within the OARP protocol.

A prediction score $\left(R^{2}\right)$ for the third reading (with intervention) thus shows that $90 \%$ of the variations in TPA scores were due to the appropriate timely interventions from teachers. The result also shows that the remaining $10 \%$ of the variations in TPA could not be explained and may be due to factors influencing the reading difficulties of students (see Figure 5).

The reading speed (RS) of students (without intervention) reveals a sharp increase from fast to slow reading cohorts (5.5\% to $44 \%$ ). There is also a sharp decline from the slow reading cohorts to the very slow reading cohorts (without intervention). There appear to be a gentle increase $(9.9 \%$ to $31.9 \%)$ in the fast reading cohorts to the slow reading cohorts (with intervention) for the second reading. The third reading thus shows a much better progress in the results of the reading cohorts. Fast to moderate readers thus show a cumulative improvement (Figure 6). This was explained by the corresponding decline in the results of the slow to very slow reading cohorts for the third reading with intervention. The implication is that the proportions of fast to moderate readers increase with teacher intervention as opposed to reading without teacher intervention.

The results further showed that the majority of the students were average-to-slow readers without teacher intervention (Figure 6). However, teacher interventions have the potential of changing average-to-slow readers to fast-to-moderate readers.

Analysis of variance was computed between the first reading (without intervention) with the second and third readings (with intervention). The results show no significant difference $(p>0.05)$ between first reading and second reading. However, there was a significant difference $(p<0.05)$ between first reading and the third reading (Table 4$)$. What this means is that reading with intervention could have positive effect on TRA, TPA and RS among students within community schools. 
Table 4 ANOVA Table for Reading with/without Intervention

\begin{tabular}{|c|c|c|c|c|c|c|c|}
\hline & & Sum of Squares & df & Mean Square & $\mathbf{F}$ & Sig. & Level of sig \\
\hline \multirow[t]{2}{*}{ 1st reading with no intervention } & Between Groups & 2692.744 & 11 & 244.795 & 1.796 & & \\
\hline & Total & 13463.297 & 90 & & & & \\
\hline \multirow[t]{2}{*}{2 nd reading with intervention } & Between Groups & 5177.875 & 11 & 470.716 & 1.743 & .079 & $(p>0.05)$ \\
\hline & Total & 26516.110 & 90 & & & & \\
\hline \multirow[t]{2}{*}{ 3rd reading with intervention } & Between Groups & 9788.449 & 11 & 889.859 & 2.498 & .010 & $(\mathrm{p}<0.05)$ \\
\hline & Total & 37927.187 & 90 & & & & \\
\hline
\end{tabular}

Independent variable: teacher intervention

Source: Fieldwork, 2019

Plates 1 and 2 show classroom situations of students with various reading practices at the time of the study with and without teacher intervention.

\section{Reading Frequency Relationships and Dynamics of Students}

\section{Frequency of Reading}

From the results, it can be seen that students only read at school or home (Table 5). Results also show that students read daily and irregularly both at school and at home. Results further show that an aggregate of $76 \%(n=91)$ of the students read daily at school as against about $28 \%(n=91)$ who read daily at home. It can also be seen that about $10 \%$ of the proportion of students who read daily at schoo/ have no regular reading patterns and could not tell their reading frequencies and durations as compared to $5 \%$ of those who read at home.

The study also found that out of the proportion of students who read daily at school, $32 \%$ read thrice daily as against just one percent $(1 \%)$ of those who read at home at the same reading frequency (thrice). Once again, the results show that $14 \%$ of the students read twice daily at school as against about $22 \%$ who read at home daily. The results again show that students who have irregular reading habits at school represented $24 \%(n=91)$ as against $72 \%(n=91)$ for those who read at home.

Table 5 Frequency and locational dynamics of reading 


\begin{tabular}{|c|c|c|c|c|}
\hline & \multicolumn{2}{|c|}{ Daily at school } & \multicolumn{2}{|c|}{ Daily at home } \\
\hline & Frequency & Percent & Frequency & Percent \\
\hline Once & 19 & 20.4 & 20 & 21.5 \\
\hline Twice & 13 & 14.0 & & \\
\hline Thrice & 30 & 32.3 & 1 & 1.1 \\
\hline Can't tell & 7 & 9.7 & 3 & 5.4 \\
\hline Total & 69 & 76.4 & 24 & 28 \\
\hline & \multicolumn{2}{|c|}{ Weekly at school } & \multicolumn{2}{|c|}{ Weekly at home } \\
\hline \multicolumn{5}{|l|}{ Once } \\
\hline \multicolumn{5}{|l|}{ Twice } \\
\hline \multicolumn{5}{|l|}{ Thrice } \\
\hline \multicolumn{5}{|l|}{ Can't tell } \\
\hline \multicolumn{5}{|l|}{ Total } \\
\hline & \multicolumn{2}{|c|}{ Monthly at school } & \multicolumn{2}{|c|}{ Monthly at home } \\
\hline \multicolumn{5}{|l|}{ Once } \\
\hline \multicolumn{5}{|l|}{ Twice } \\
\hline \multicolumn{5}{|l|}{ Thrice } \\
\hline \multicolumn{5}{|l|}{ Can't tell } \\
\hline \multicolumn{5}{|l|}{ Total } \\
\hline & \multicolumn{2}{|c|}{ Irregular at school } & \multicolumn{2}{|c|}{ Irregular at home } \\
\hline Irregular & 22 & 23.6 & 67 & 72.0 \\
\hline Total & 22 & 23.6 & 67 & 72.0 \\
\hline Total & 91 & 100.0 & 91 & 100.0 \\
\hline
\end{tabular}

Source: Fieldwork, 2019

\section{Reading Difficulty Dynamics and Interventional Model (RDDIM), an Empirical Analysis}

Figure 7 shows an empirical analysis of reading difficulty dynamics and interventions of the respondents. The paper identified four causative factors (viz. internal, biological, genetics and external) for reading difficulties among students and three locational dynamics (viz. at school, outside school/home and at home) of reading difficulties, four durational dynamics (<1 hr, 1-2 hrs, 2-3 hrs, >4 hrs) of reading difficulties, four reading frequency dynamics (viz. daily, weekly, monthly, and irregularly) of reading difficulties and four periodic dynamics (viz. once, twice, thrice, and irregular) of reading difficulties.

The paper thus presents the dynamics of and relationships between these dimensions of reading difficulties based on data and the results of this study. The difference between this model and the conceptual framework (Figure 1) is that this model (Figure 7) is based on data and results of the study whilst the former is based on knowledge and conceptualization from literature.

The results of RDD summarily show that;

LD1 is $76 \%(n=91)$ whilst LD3 is $28 \%(n=91)$ for those who read daily within reading difficulty dynamics (RFD). LD2 had no results for RFDs in this study. FD3 and FD4 also had no results. There are however mixed results for the frequency dynamics (FD1, FD2, FD5, and FD6) and durational dynamics (DD). The irregularity of reading also has mixed results. There is a positive significant correlation between first locational dynamics (LD1) and DD. There is a weak inverse (negative) relationship between LD3 and DD, probably because the majority of irregular readers could not tell their reading durations.

The paper proposes that due to the evidence-based nature of this analytical model, though the empirical results on which it is premised are not nationally representative, it has the potential of reducing reading difficulties in schools. The paper also proposes that this analytical model be termed Reading Difficulty Dynamics and Interventional Model (RDDIM). The paper further proposes that the underlining assumptions of this model are premised on teacher intervention, students' compliance, and practice. 


\section{Reading Frequency, Durational and Locational Dynamics of Students}

The study further found there is a relationship between reading frequency, durational, and locational dynamics of reading at school. The cohorts of students who read once for less than $1 \mathrm{hr}$ represent $6 \%(n=84)$ whilst those who read between $1-2$ hrs represent about $10 \%$ and those who read for $3-4$ hrs represent $1 \%$ with $6 \%$ for those who did not know how long they read once per day at school. Students who read twice per day at school for less than $1 \mathrm{hr}$ represent $8 \%$ followed by $6 \%$ for those who read 1-2 hrs and 1\% for those who read 3-4 hrs. Students who read thrice per day at school for less than $1 \mathrm{hr}$ represent $7 \%$ followed by $14 \%$ each for $1-2 \mathrm{hrs}$ and $3-4 \mathrm{hrs}$. Students with irregular reading patterns also represent $26 \%$ in total as presented in Table 6.

Table 6 Relationship between Reading Frequencies, Durational and Locational Dynamics

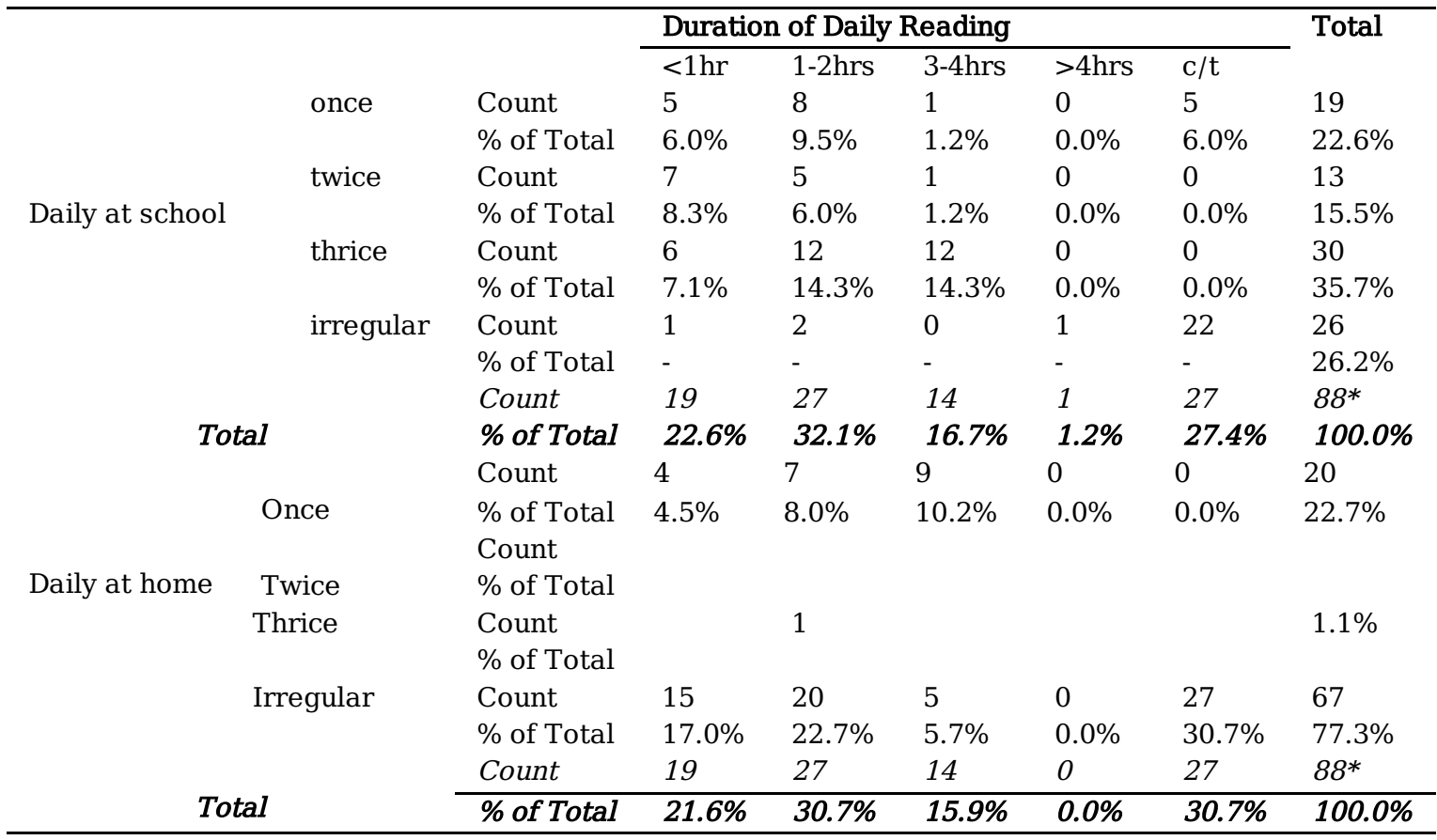

c/t: cannot tell $\quad$ * missing systems: 3

Source: Fieldwork, 2019

The test result shows that there is a strong positive relationship between reading frequency and durational dynamics among the students at school using the Pearson Chi-Square. The relationship is shown to be significant $(p<0.05)$ at the $5 \%$ confidence interval (Table 7). A further test to establish a relationship between locational (at home) and durational (hours) dynamics conversely show a negative relationship which is significant $(p<0.05)$ at the $5 \%$ confidence interval.

Table 7 Pearson Chi-Square and Correlation Tests for Reading Frequency Dynamics 


\begin{tabular}{llcc}
\hline Correlations Tests & & Daily at school & duration of daily reading \\
\hline Daily at school & Pearson Correlation & 1 & $.540^{* *}$ \\
& Sig. (2-tailed) & & .000 \\
duration of daily reading & $\mathrm{N}$ & 88 & 88 \\
& Pearson Correlation & $.540^{* *}$ & 1 \\
& Sig. (2-tailed) & .000 & 88 \\
Daily at home & $\mathrm{N}$ & 88 & $-.223^{*}$ \\
& Pearson Correlation & 1 & .037 \\
& Sig. (2-tailed) & & 88 \\
duration of daily reading & $\mathrm{N}$ & 88 & 1 \\
& Pearson Correlation & $-.223^{*}$ & \\
& Sig. (2-tailed) & .037 & $\mathbf{8 8}$ \\
\cline { 2 - 4 } & $\mathbf{N}$ & $\mathbf{8 8}$ & \\
\hline
\end{tabular}

a. 12 cells (60.0\%) have expected count less than 5. The minimum expected count is .15.

**. Correlation is significant at the 0.01 level 2-tailed

Plate 3 shows a cohort of students demonstrating peer reading with and without teacher intervention.

\section{Reading Difficulty Interventions}

Table 8 presents students' responses on the reading difficulty interventions that helped in their reading of the 100-worded paragraph using the OARP protocol. Earlier, the positive effects of reading interventions on reading difficulties show increasing trends for TRA, TPA, RS among others. Here, the results further validate the findings in Figures 4, 5 and 6. According to students multiple responses, $19 \%$ each $(n=312)$ of the total number of multiple responses cited repeated and paired reading interventions to have had a positive effect on their reading abilities whilst $21 \%$ have cited word drills and dictations.

Table 8 Reading Difficulty Interventions

\begin{tabular}{llcc}
\hline & Reading interventions & \multicolumn{2}{c}{ Multiple Responses } \\
\cline { 3 - 4 } Multiple & & $\mathbf{N}$ & Percent \\
Interventions & a & 60 & $19.2 \%$ \\
& Repeated reading & 64 & $20.5 \%$ \\
& Assisted reading & 60 & $19.2 \%$ \\
& Paired reading & 64 & $20.5 \%$ \\
& Guided reading & 64 & $20.5 \%$ \\
\hline Total & word drills and dictation & $\mathbf{3 1 2}$ & $\mathbf{1 0 0 . 0 \%}$ \\
\hline
\end{tabular}

a. Dichotomy group tabulated at a value $\quad$ Source: Fieldwork, 2019

\section{Discussion Of Results}

\section{Causes of Reading Difficulties}

The findings of the study suggest that several causative factors influence students' reading difficulties which were internal as found in earlier studies (Sani et al., 2011; Peterson et al., 2000), external as found by Issa et al.,( 2012), biological (Lagae, 2008) and genetic as also found by researchers such as Harlaar, et al., (2007) and Snowling et al., (2003). This result also agrees with Guthrie \& Wigfield (2000) who found that internal factors such as lack of motivation and lack of interest (Issa et 
al., 2012) are the major contributors to students' reading difficulties. The present study also reveals that fear of making mistake in class and farming chores constitute external factors to reading difficulties.

The internal causative factors in this study agrees with Peterson et al., (2000) who have found that a group of secondary students with reading difficulties were affected by their tendency to avoid reading (internal factors). The results of the study also agree with the findings of Sani et al., (2011) and Peterson et al., (2000) who found that as students move through the grades, especially at the middle school level, their motivation to read tends to decline. Other studies (Snowling, et al., 2003; Lagae, 2008; Harlaar, et al., 2007) also confirm biological factors such as disorders, sicknesses and disabilities being responsible for students reading difficulties. The interview accounts with the key informants point out to the fact that students could have foundational issues probably from their basic levels of education vis-a'-vis reading abilities which translated into their existing reading difficulties.

Indeed, changing these trends thus require multiple interventions and cooperation from both students and teachers. Though the genetic investigation and attribution in this paper is not exhaustive to warrant a strong genetic conclusion on reading difficulties, the limited evidence of genetic factors found as also reported by Snowling et al., (2003), is suggestive of genetic causality of reading difficulties. Therefore, an extensive study on the family histories and academic performance (e.g. reading) is good for future research. Several studies (Lagae, 2008; Harlaar, et al., 2007) also confirm biological factors such as disorders, sicknesses, and disabilities being responsible for students reading difficulties.

\section{Assessment of Reading Difficulties}

Reading difficulties were measured by students' inabilities to effectively and efficiently read, recognize, pronounce, and speedread a 100-worded paragraph within one minute using the OARP protocol. The paper notes that students' reading difficulties could be due to external, internal, biological, or genetic factors experiences such as sicknesses, defects, disabilities, and abnormalities as found in Figure 8.

The first reading (without intervention) produced TRA, TPA, and RS scores below the $80 \%$ benchmark set in this study. Students' first readings were without teacher intervention. The paper notes that the majority of the students sampled in the study had reading difficulties as also found by Ambe (2007) and Neumann et al., (2008) in their studies that many students struggle with reading difficulties. The study also found strong evidence of improvement in TRA, TPA and RS scores after teacher interventions. Thus, about half $(n=91)$ of the respondents had TRA and TPA scores above the $80 \%$ benchmark during the third reading (with intervention). This shows that students' reading difficulties can be improved or overcome when timely teacher intervention is applied. This is also confirmed by the prediction values of $91 \%$ for TRA and $90 \%$ for TPA. What these imply are that about $9 \%$ to $10 \%$ of the variations in TRA and TPA scores could be explained by other factors.

In this study, RS was measured as Fast (up to 100 wpm), Moderate (up to $80 \mathrm{wpm}$ ), Slow (up to 60 wpm) and Very slow ( $<60$ wpm). The results showed that the majority of the students were average-to-slow readers without teacher intervention (Fig 7). Cumulatively, these results of reading difficulties are consistent with earlier works of Ambe (2007) and Neumann et al., (2008) who in their studies conclude that many students struggle with reading difficulties. Thus, teacher interventions have the potential of changing slow-to-average readers to moderate-to fast readers which is an indication of a significant improvement in the Reading Speed (RS) scores.

\section{Reading Difficulty Dynamics of Students}

- Locational and Frequency Dynamics of Reading Difficulties

Page 16/27 
The findings seem to suggest that majority of students who read once at home within the locational dynamics could be doing so because the school is not a boarding school and situated in the midst of adjoining communities. It also appears that those who prefer to read at home do so in response to hunger (going home to cook and/or eat and do house chores). This is probably because the school is a day school and students had to go home after school closes. The above observation further seemed to point to the fact that because students spend a minimum of $8 \mathrm{hrs}$ in school and have 7 different teachers take them through 7 different courses per day, they were more likely to read frequently at school than at home. School starts at 07:00 hours and closes at 15:00 hours with two break sessions.

Again, due to the economic condition of most households in the communities, most students tend to bring their meals to school and would thus be in a hurry to go home to prepare and eat their evening meals. This, therefore, explains why the majority of students tend to have irregular reading habits and abilities at home. These results are consistent with the findings of Ambe, (2007) and Neumann et al., (2008) who in their studies cited incidences of hunger and poverty as external causative factors to reading difficulties. The results also agree with the findings of Texas Education Agency, (2001) who found that alternate word-level activities (two times per week) with practice reading connected text (three times per week) to provide the practice students need to read words quickly and accurately both in isolation and in connected texts.

The dominance of irregular reading habits at home by the majority of students is consistent with the reality that the school is a Community Day School. What this means is that students live/reside in the communities and commute short distances to school for their studies. At present, hostel facilities are available within the school premises (for the girls) and just very close to the school (for the boys) at a fee whilst the rest live in town.

\section{- Locational, Durational, Frequency and Periodic Dynamics of Reading Difficulties}

The paper discovered multiple relationships between the locational, durational, frequency, and periodic dynamics of Reading Difficulties at school and home. There seemed to be more frequent readers at school than at home and that those who read thrice daily at school represented $26 \%$ as against just one percent (1\%) at home. The duration of reading for those who read thrice daily at school for $<1 \mathrm{hr}$ increased from seven percent (7\%) to fourteen percent (14\%). There is positive significant $(p<0.05)$ relationship between locational, frequency, and durational dynamics of reading difficulties. The implication is that the frequency of reading is higher in school than at home because of the available facilities in the school. These facilities include state of the art library, extra classrooms, serene atmosphere, and school laboratories.

Contrarily, the paper notes that the frequency of reading irregularly is higher at home than at school within the locational, durational and frequency dynamics. The results, therefore, seem to rule out the locational (reading at home) dynamics relationship with durational dynamics. This is because the results show a weak negative relationship between reading at home and durational dynamics. One probable reason accounting for this result could be the larger proportion of irregular readers who could not tell their reading durations.

\section{Reading Difficulty Interventions}

The findings of this paper thus show that repeated reading, assisted reading, paired reading, guided reading, text recognition and text pronunciation with appropriate reading speed could be used as interventions to overcome students reading difficulties. These results agree with the findings of Mathes \& Fuchs (1994) and Neumann et al., (2008) who found that guided reading fluency increases reading skills. The results further agree with the findings of Wawryk-Epp et al., (2004) who also found that repeated reading, paired reading, choral reading, corrective feedback and readers' theatre improve reading fluency among learners, thus, reducing reading difficulties among students.

\section{Conclusion, Policy Recommendation And Suggestion For Future Research}

\section{Causes of Reading Difficulties}

Page $17 / 27$ 
The paper concludes that multiple factors are responsible for students reading difficulties. These include internal, external, and biological and genetic factors. There is however, insufficient data on the genetic factors as limited evidence point to that claim.

\section{Assessment of Reading Difficulties}

All the students had text recognition, text pronunciations, and reading speed problems without teacher interventions. Nevertheless, students reading difficulties reduced with timely teacher interventions which have implications for innovative teaching and policy direction in community schools.

\section{Reading Difficulty Dynamics}

Four different dynamics (locational, durational, frequency, and periodic) had mixed results on reading difficulties. Within the locational and frequency dynamics, it is concluded that students tend to read more frequently at school than at home.

Students however tend to read more irregularly at home than at school because the school is a community day school. The majority of students who read irregularly at home have no records of their reading durations. However, those who also tend to read more in the school daily do so because they live a hostel/ homes near the school and have study groups who prefer to go to the campus to learn together. It is also concluded that either students read at school or home and that students do not read outside school and home within the locational dynamics. There are however mixed results for the frequency dynamics (FD1, FD2, FD5, and FD6) and durational dynamics (DD). That said large proportions of students tend to read twice and thrice daily at school for 1-2 hrs and 3-4 hrs respectively. The irregularity of reading also has mixed results.

There is a positive significant correlation between first locational dynamics (LD1, reading at school) and durational dynamics. There is a weak negative relationship between third locational dynamics (LD3) and durational dynamics, probably because the majority of irregular readers could not tell their reading durations.

\section{Reading Difficulty Interventions}

The major interventions that could help students overcome their reading difficulties include repeated reading, assisted reading, paired reading and guided reading towards text recognition, text pronunciations and appropriate reading speed.

\section{Policy Recommendations}

It is recommended that;

- Community Schools should set up reading clubs under the supervision of English language tutors to promote reading between and among students in school. This is to make reading a common practice within and outside school. Teachers should also give students weekly reading assignments towards improving their reading skills and overcoming reading difficulties.

- Students should be made to read openly at all school gatherings, where applicable. These include gatherings like worship services, open forums, open ceremonies, and the like. By so doing, their oral mistakes can be identified and corrected after the said gatherings. This approach will also gradually boost confidence in the students and urge other students to emulate open reading. If this is done consistently, it will have a positive impact on the oral/spoken English of students towards academic performance and national development.

\section{Suggestion for Future Research}


This study should be repeated in other community schools in the country in order to assess the country's prevalence of the phenomenon towards validating the Reading Difficulty Intervention Model developed in this study. This study should also be repeated every three years to assess the progression of the phenomenon among community schools.

\section{Limitations of the study}

This study is not a generalization of reading difficulty dynamics and intervention in all community schools in Ghana. The study is thus limited to the Banka Community SHS in the Asante Akyem South Municipality of Ghana. The study, thus, presents these findings as contributions to an emerging academic problem within community schools in Ghana which could have implications for SDG 4 in the next decade. The study also made limited genetic attributions of reading difficulty, as data on respondents' family histories were not extensive.

\section{References}

Acheaw, M. O., \& Larson, A. G. (2014). Reading Habits among Students and its Effects on Academic Performance: A Study of Students of Koforidua Polytechnic. Library Philosophy and Practice (e-journal), 1130, 1-22. Online: http://www.digitalcommons.unl.edu/libphilprac (Accessed 2/2/19)

Alber-Morgan, S. R., Ramp, E. M., Anderson, L. L., Martin, C. M. (2007). Effects of repeated readings, error correction, and performance feedback on the fluency and comprehension of middle school students with behavior problems. The Journal of Special Education, 41(1), 17-30

Alvarez, B. (2016). The relationship of self-reported reading habits and declarative memory.

Aitchison J and Alidou, H (2009). The State and Development of Adult Learning and Education in Sub-Saharan Africa: Regional Synthesis Report UNESCO Institute for lifelong learning. Feldbrunnenstraße 58, Germany. Online at http://www.unesco.org/fileadmin/Multimedia/Institutes/UIL/confintea/pdf/GRALE/confinteavi_grale_africa_synthesis_en.pdf (Accessed 2/02/2019)

Ambe, E. B. (2007). Inviting reluctant adolescent readers into the literacy club: Some comprehension strategies to tutor individuals or small groups of reluctant readers. Journal of Adolescent \& Adult Literacy, 50(8), 632-639

Baggio, G., \& Fonseca, A. (2012). Complex dynamics of semantic memory access in reading. Journal of the Royal Society, 9 , 328-338. DOI:10.1098/ rsif.2011.0289

Bettinger, E., \& Long, B. T. (2009). Addressing the needs of underprepared students in higher education: Does college remediation work? Journal of Human Resources, 44(3), 736-77

Booth A., (2003). Teaching History at University: Enhancing Learning and Understanding. Routledge. Taylor and Francis Group. London and New York. pp 32-102

Cain, K., Oakhill, J., \& Bryant, P. (2004). Children's reading comprehension ability: Concurrent prediction by working memory, verbal ability, and component skills. Journal of Educational Psychology, 96, 31-42

Chard, D. J., Vaughn, S., \& Tyler, B. (2002). A synthesis of research on effective interventions for building reading fluency with elementary students with learning disabilities. Journal of Learning Disabilities, 35. 386-407

Creswell, J. W. (2013). Research design: Qualitative, quantitative, and mixed methods approach. Thousand Oaks: Sage Publications.

Friend, A., Defries, J. C., \& Olson, R. K. (2008). Parental education moderates genetic influences on reading disability: Research article. Psychological Science, 19(11), 1124-1130. Online: https://doi.org/10.1111/j.1467-9280.2008.02213.x (Accessed 
Fuchs, D., Mathes, P. G., \& Fuchs, L. S. (1996). Peabody Peer-Assisted Learning Strategies (PALS): Reading methods (rev. ed.). (Available from Douglas Fuchs, Box 328, George Peabody College, Vanderbilt University, Nashville, TN 37203).

Fuchs, L. S., Fuchs D., \& Hosp, M. K. (2001). Oral reading fluency as an indicator of reading competence: A theoretical, empirical, and historical analysis. Scientific Studies of Reading, 5(3), 239-256.

Foley B., (2018). Survey Tips. Purposive Sampling 101.Survey Gizmo. 4888 Pearl East Cir. Suite 100W Boulder, CO 80301 USA.

Ghana Library Authority, (2019). 2019, the Year of Reading.

Ghana Association of Science Teachers (GAST), (2001). Integrated Science textbook for Senior Secondary Schools. $1^{\text {st }}$ edition. Macmillan. Accra Ghana.

Guthrie, John \& Laurel W. Hoa, A \& Wigfield, Allan \& Tonks, Stephen \& M. Humenick, Nicole \& Littles, Erin. (2007). Reading motivation and reading comprehension growth in the later elementary years. Contemporary Educational Psychology. 32. 282313. 10.1016/j.cedpsych.2006.05.004.

Guthrie, J. T., \& Wigfield, A. (2000). Engagement and motivation in reading. In M. L. Kamil, P. B. Mosenthal, P. D. Pearson, \& R. Barr (Eds.), Handbook of reading research, Vol. III (pp. 403-422). Mahwah, NJ: Erlbaum.

Government of Ghana. (2016). Republic of Ghana the Composite Budget of the Kintampo South District 2016 Fiscal Year. Government of Ghana, 1(1), 1-84. Online: https://doi.org/10.1016/j.jhydrol.2004.07.007

Gruenbaum E. A. (2012). Common Literacy Struggles with College Students: Using the Reciprocal Teaching Technique. Journal of College Reading and Learning, 42(2), 110-116.

Harlaar, N., Dale, P.S., and Plomin, R. (2007). From learning to read to reading to learn: Substantial and stable genetic influence. Child Development. 78.1 116-131. Print.

Huang, Ling-yan, \& Luo, Jian-ping. (2011. 7). Correlation Analysis of Reading Comprehension in CET4 Based on Corpus. Journal of Shaoguan University, 2011(7), 81-83.

Issa, A. O., Aliyu, M. B., Akangbe, R. B. \& Adedeji, A. F.(2012) Reading Interest and Habits of the Federal Polytechnic Students. International Journal of Learning \& Development.Vol.2, No.1, pp 470-486

Lagae, L. (2008). Learning Disabilities: Definitions, Epidemiology, diagnosis, and intervention strategies. Pediatric Clinics of North America. 55. 1259-1268. Print.

Luo, J. (2013). An Action Research on Improvement of Reading Comprehension of CET 4. English Language Teaching. Canadian Center of Science and Education, 6(4), 89-96. Online: https://doi.org/10.5539/elt.v6n4p89

Manning, C. L. (1997). The new book of knowledge. USA; New York: Grolier. In: Orakpor M.A., (2012). Comparative Study of the Reading Habits of Theological and Management Students Of St. Paul's University College, Awka. Department Of Library and Information Science University Of Nigeria, Nsukka.

Mathes, P. G., \& Fuchs. L. S. (1994). The efficacy of peer tutoring in reading for students with mild disabilities: A best-evidence synthesis. School Psychology Review, 23, 59-80.

Marilee, S. B. (2013). Wiring the brain for reading: brain-based strategies for teaching literacy. San Francisco: John Wiley \& Sons. 
National Educational Psychological Science. (2012). Effective Interventions for Struggling Readers A Good Practice Guide for Teachers (Mary Nugen, pp. 1-42). NEPS Literacy Working Party.

Neugebauer, S.R., (2013). A daily diary study of reading motivation inside and outside of school: A dynamic approach to motivation to read.

Online: https://doi.org/10.1016/j.lindif.2012.10.011Get rights and content. (Accessed 12/2/19)

Neumann, V. S., Ross, D. K., \& Slaboch, A. F. (2008). Increasing Reading Comprehension Of Elementary Students Through Fluency-Based Interventions. Saint Xavier University \& Pearson Achievement Solutions., Inc.Chicago, Illinois.

Pawlowski, J., Remor, E., Pimienta, M. P., Fumagalli de Salles, J., \& Rochele, P. (2012). The influence of reading and writing habits associated with education on the neuropsychological performance of Brazilian adults. Read Writ, 25, 2275-2289. doi:10.1007/s11145-012-9357-8

Peterson, C. L., Caverly, D. C., Nicholson, S. A., \& Cusenbary, S. (2000). Building Proficiency At The Secondary Level. A Guide to Resources. U.S.

Rasinski, T. (2004). Creating fluent readers. Educational Leadership, 61(6), 46-51.

Reading Comprehension: Theory and Practice. (2000). Chapter one. Reading Comprehension: Theory and Practice.

Research-Based Programs on English Mathematics and Science in Schools. (2012). Research-Based Programs and their Findings.

Research-Based Interventions Strategies on Reading. (2000). Research-Based Interventions / Strategies.

Sani B.B., Chik M.N.B.W., Nik Y.B.A., and Raslee N.A.B., (2011). The Reading Motivation and Reading Strategies Used by Undergraduates in University Teknologi MARA Dungun, Terengganu. ISSN 1798-4769 Journal of Language Teaching and Research, Vol. 2, No. 1, pp. 32-39. Academy Publisher Manufactured in Finland. doi:10.4304/jltr.2.1.32-39

Sanford, K. L. (2015). Factors that Affect the Reading Comprehension of Secondary Students with Disabilities.

Sheridan, E. M. (1981). Theories of Reading and Implications for Teachers. Reading Horizons, 22(1), 66-71. https://doi.org/10.2307/24707568

Singh, Y. G. (2011). Academic Achievement and Study Habits of Higher Secondary Students. International Referred Research Journal, 3 (27), ISSN- 0975-3486, RN.

Snowling, M. (2004). The science of dyslexia: A review of contemporary approaches. The Study of Dyslexia. Ed. M. Turner and Ed. J. Rack.New York: Kluwer Academic Publishers, 77-90. Print.

Swanson, H., \& O'Connor, R. (2009). The role of working memory and fluency practice on the reading comprehension of students who are dysfluent readers. Journal of Learning Disabilities, 42 (6), 548-575

Swanson, H., Zheng, X., \& Jerman, O. (2009). Working memory, short-term memory, and reading disabilities: A selective metaanalysis of the literature. Journal of Learning Disabilities, 42 (3), 260-287

Texas Education Agency. (2001). Essential Reading Strategies for the Struggling Reader: Activities for an Accelerated Reading Program. Texas, USA. Retrieved from www.texasreading.org

Texas Center for Reading and Language Arts/Texas Education Agency (1998). Professional development guide-Reading fluency: Principles for instruction and progress monitoring. Austin, TX: Texas Education Agency. 
Therrien, W. J., Wickstrom, K., \& Jones, K. (2006). Effect of a combined repeated reading and question generation intervention on reading achievement. Learning Disabilities Research \& Practice, 21(2), 89-97

Training Manual on Sample Design for Surveys. (2006). Training Manual on Sample Design for Surveys Draft 2006. This is a draft training document developed by the International Programs Center of the US Bureau of the Census for training in developing countries.

University of Southampton (2003). Reading guides. Southampton: UOS.

Van den Broek, P., Lorch, R. F., Jr., Linderholm, T., \& Gustafson, M. (2001). The effects of readers' goals on the generation of inferences. Memory \& Cognition, 29, 1081-1087.

Vaughn, S., Wanzek, J., \& Murray, C. S. (2012). Intensive interventions for students struggling in reading and mathematics. A Practice Guide (1st ed.). Florida State: Center on Instruction. Retrieved from www.centeroninstruction.org

Wawryk-Epp, L., Harrison, G., \& Prentice, B. (2004). Teaching Students with Reading Difficulties and Disabilities. A Guide for Educators. Saskatchewan Learning. Retrieved from www.canlearn.ca (Accessed 5/2/2019)

World Data Atlas Ghana Topics Education Literacy, 2019.

Online: https://knoema.com/atlas/Ghana/topics/Education/Literacy/Adult-literacy-rate. Accessed 2/2/19

\section{Declarations}

\section{Statements and Declarations}

This manuscript has not been published previously. It has not also been submitted to another journal for simultaneous consideration for publication. The authors reserve the right to publish the manuscript in any journal found suitable and credible, hence have chosen your Journal as suitable to publish this manuscript. The study was self-funded. All authors contributed to the study conception and design and have read and approved the final manuscript. Though major works and drafting were done by the lead author, several revisions and contributions were made by the co-authors at different times.

\section{Competing Interests and Compliance with Ethical Standards}

The authors have no competing financial or non-financial interests to declare that are relevant to the content of this article and that and that there are no anticipated ethical implications of this manuscript. The study was conducted based on the Free Prior Informed Consent (FPIC) principles of doing research which allows participants to willingly give their consent after a brief introduction to the study. The participants in this study were men and women in the small-scale mining. Informed consent was obtained from all respondents for being included in the study. Additional informed consent was obtained from all individuals for whom identifying information is included in this article.

\section{Acknowledgements}

Gratitude goes to Mr Samuel Apau Mensah and Mr Augustine Asare Bediako, senior lecturers at the University of Education, Winneba Kumasi campus, for their advice towards the development and completion of this research. Gratitude also goes to the teaching staff and the Heads of Departments of the Banka Community Senior High School for their supports. Credit also goes to Mr Bernard Ampiadu, Mr Joshua Kwarteng, Mr Mahama Musah Zankpaligri, Mr Alhaji Innusah Amadu (Assistant Headmaster Academics), Mr Samuel Oteng (Assistant Headmaster, Administration) and Anna Essandoh currently of Kumasi Senior High Technical School for their inspirations. Gratitude also goes to the following Headmasters of the Banka Community Senior High School; Mr Ebenezer Ofosu Aboagye and Mr Omar Ahmed Ampong for their cooperations.

\section{Plates}




\section{Figures}

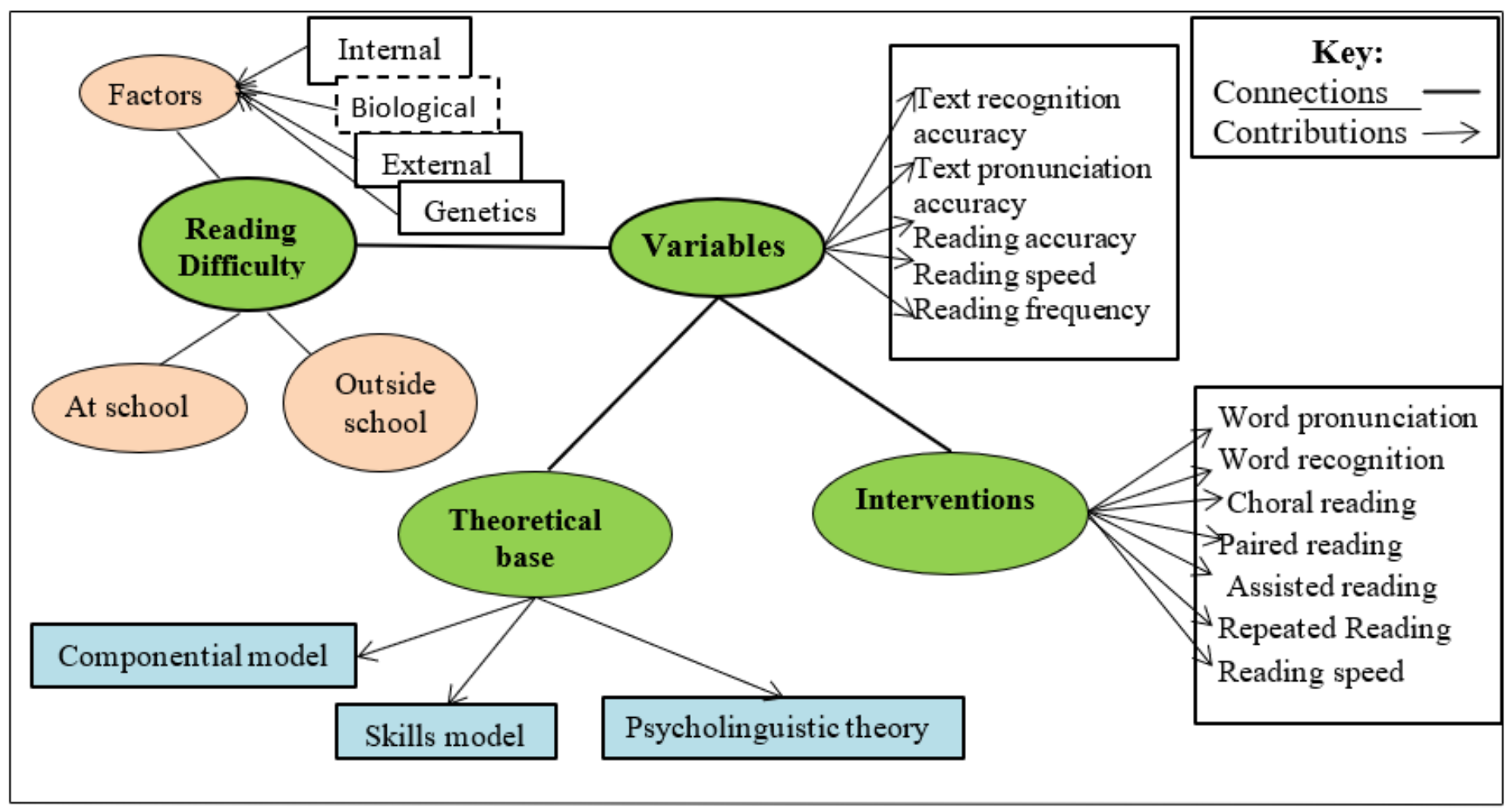

Figure 1

Conceptual framework of the study. Source: Authors' Construct 2019. 


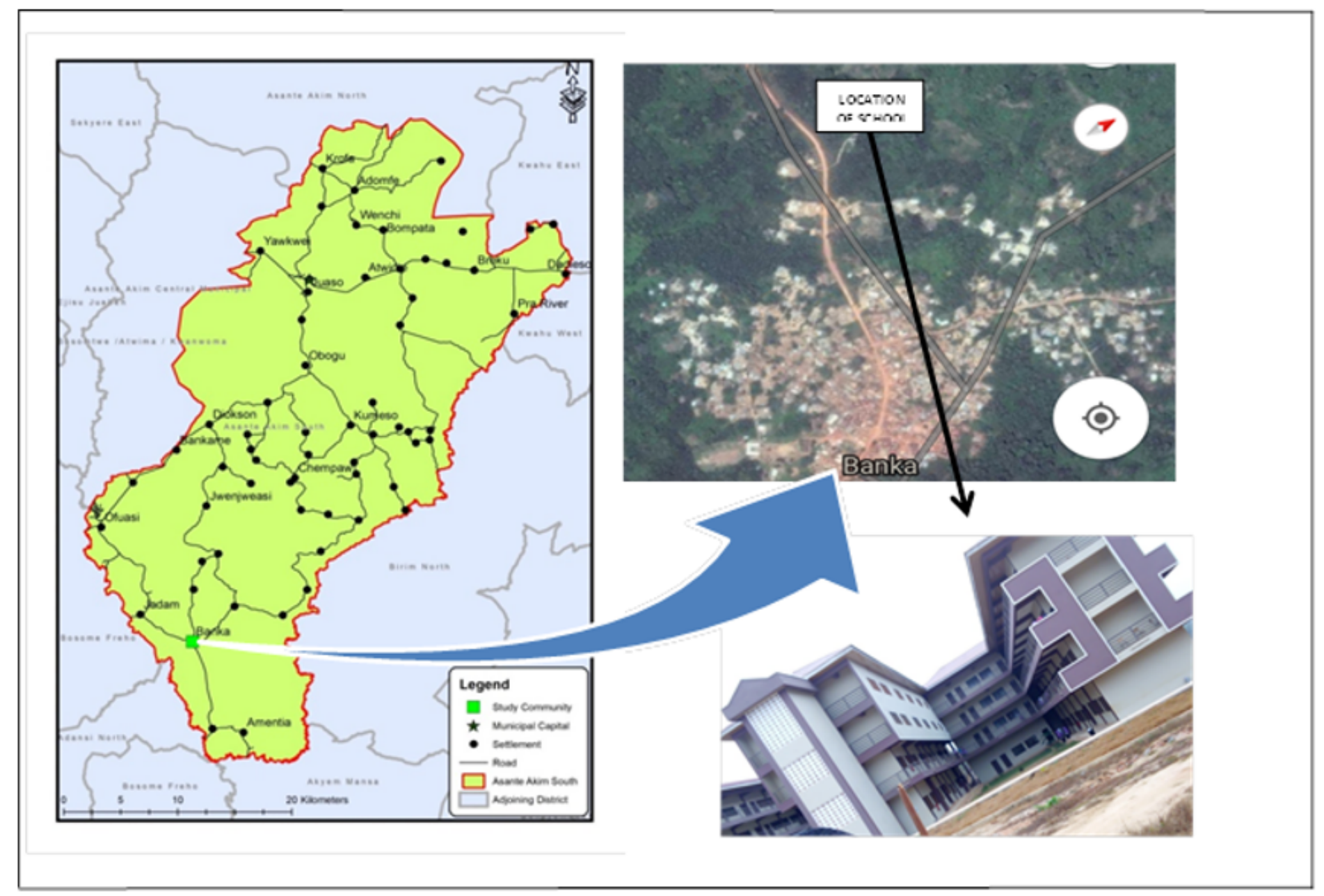

Figure 2

The Study map. Source: Authors' Construct 2019.

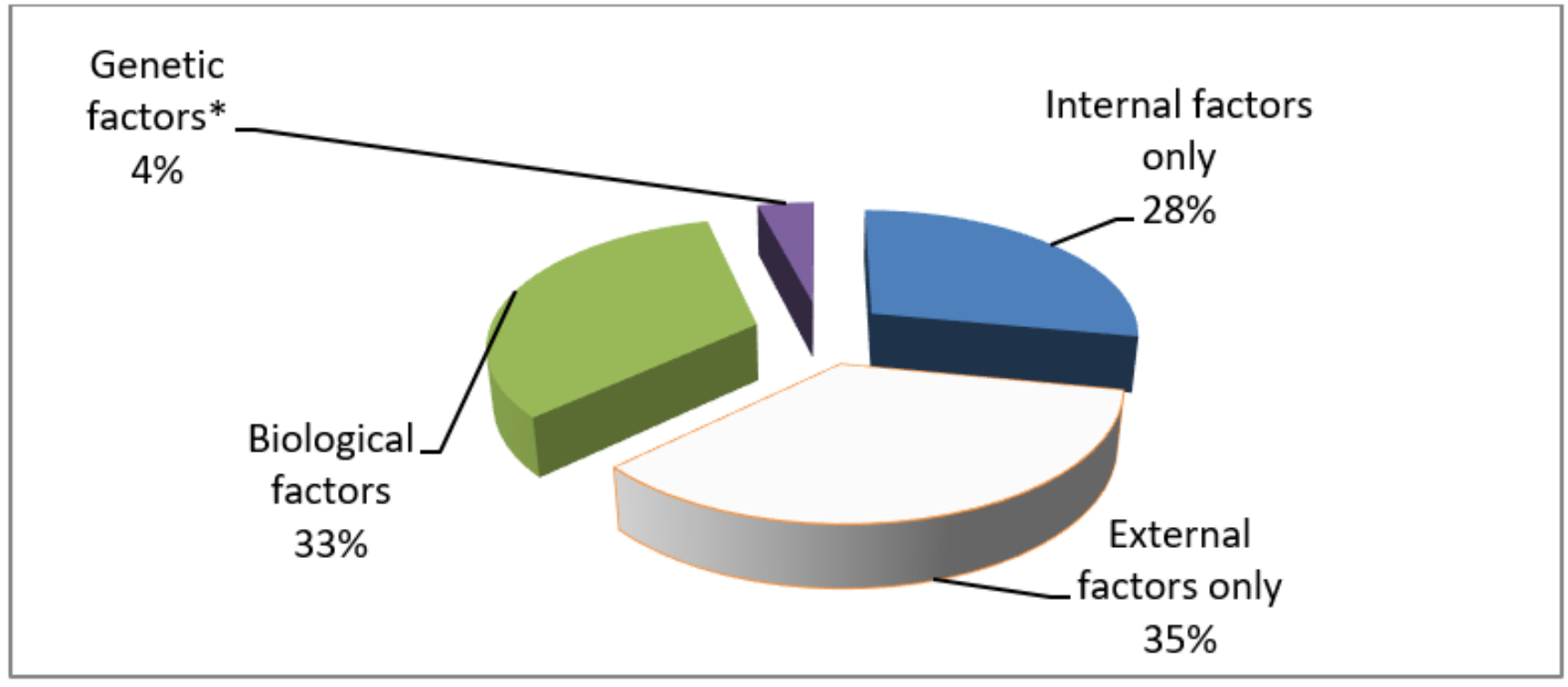

\section{Figure 3}

Causes of reading difficulties. * Whilst the study did not do an extensive genetic survey and trace of RDs on the family bloodlines, this result only points to the presence of limited genetic causative factors for RDs. Source: Fieldwork, 2019 


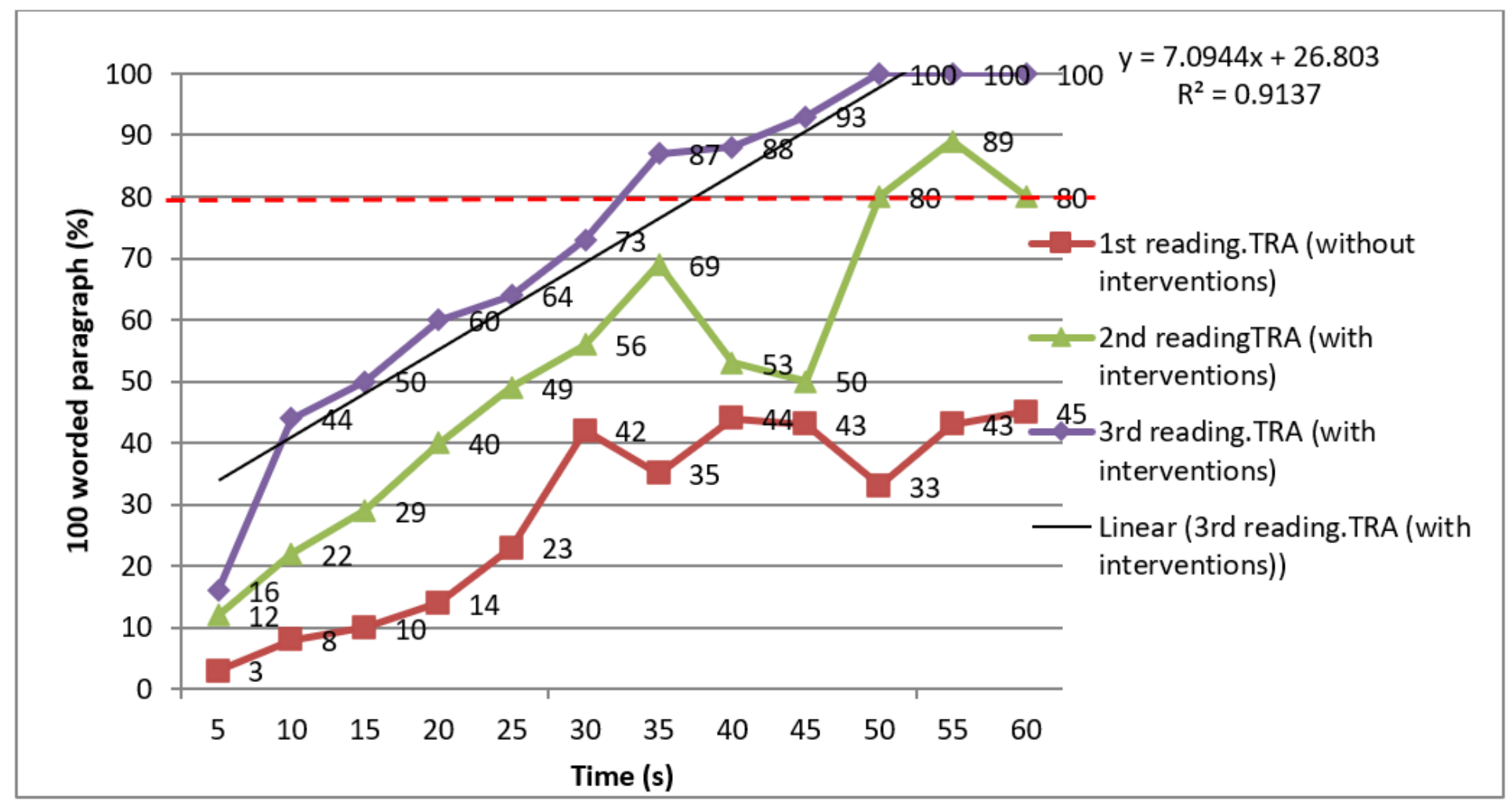

Figure 4

Text Recognition Accuracy (TRA) of students. Source: Fieldwork, 2019

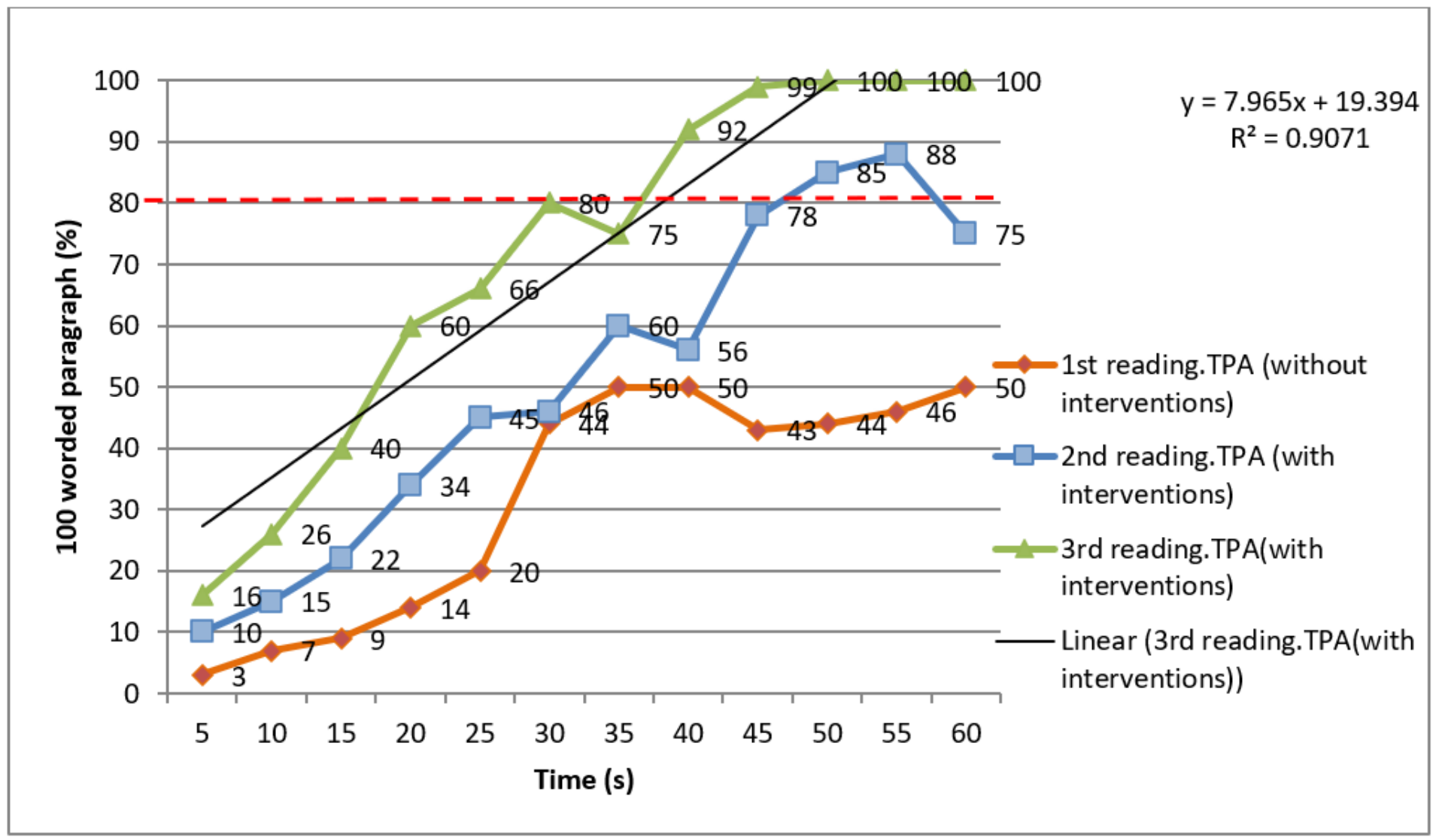

Figure 5 
Text Pronunciation Accuracy (TRA) of students. Source: Fieldwork, 2019

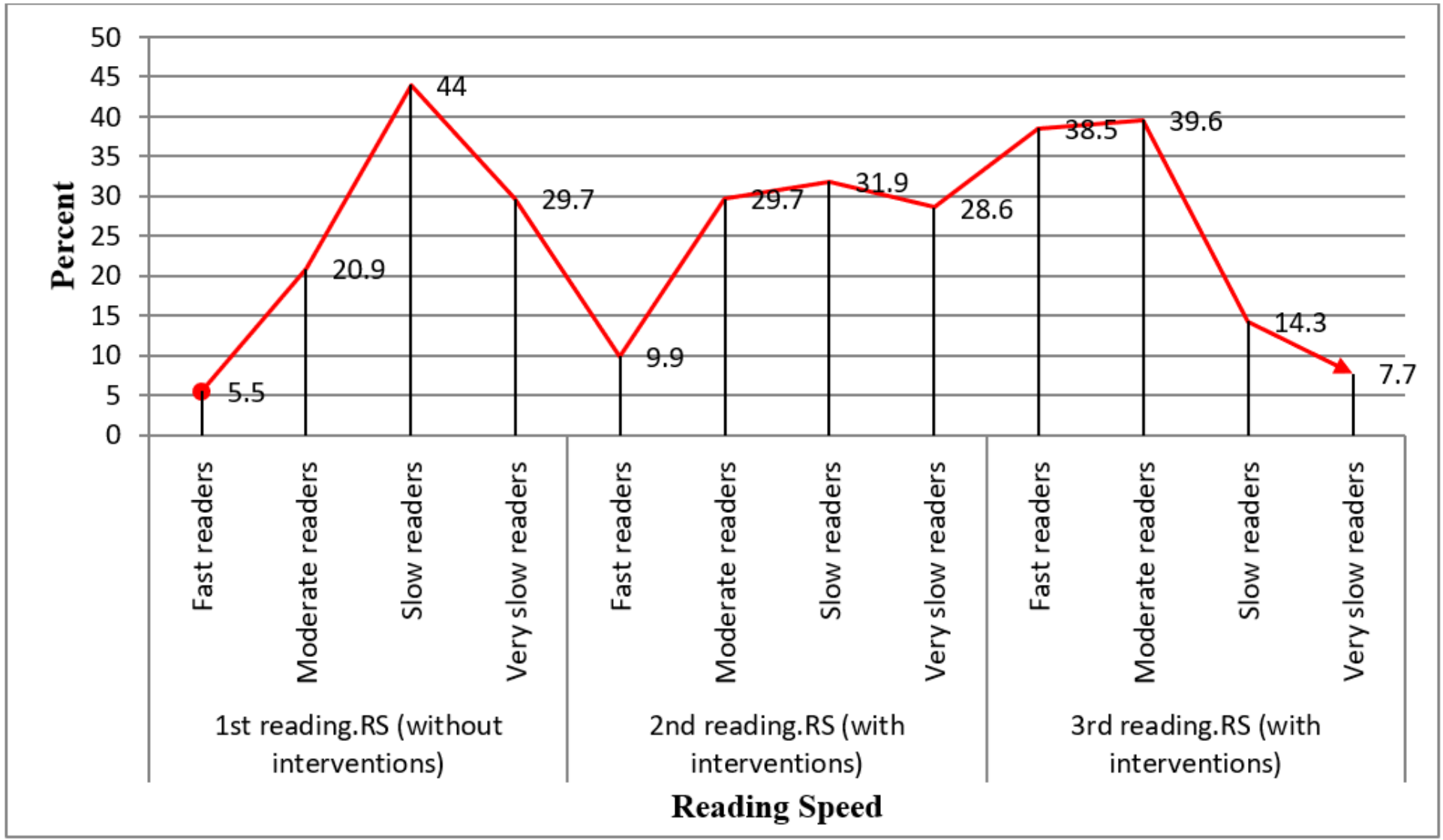

Figure 6

Reading Speed (RS) of students. Source: Fieldwork, 2019 


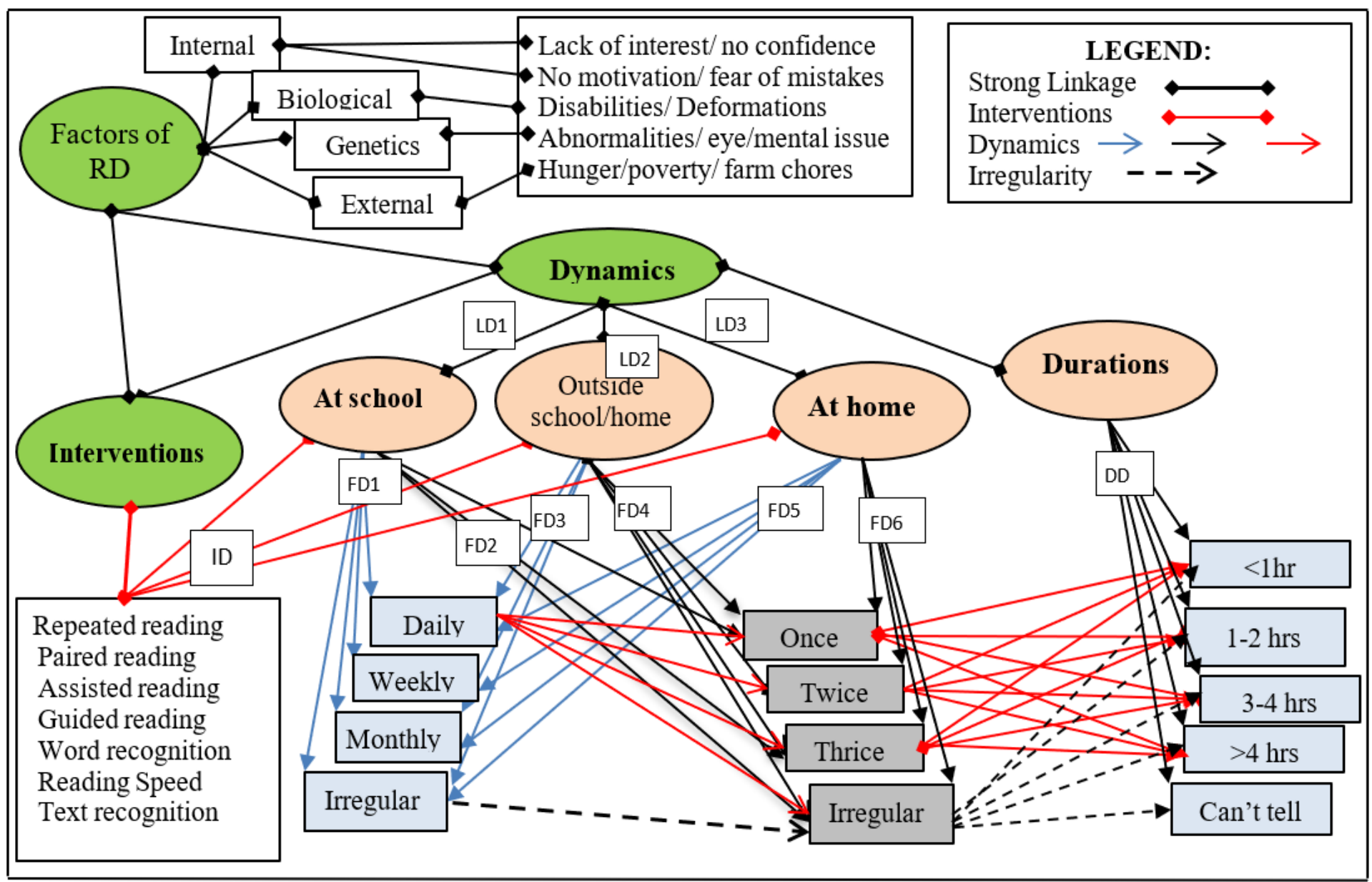

Figure 7

Situational Analysis of Reading Difficulty Dynamics and Interventions. Source: Authors' Construct 2020. RD: Reading Difficulty LDs: Locational dynamics RDDs: Reading Difficulty Dynamics LD1: Locational Dynamics 1 (reading at school) LD2: Locational Dynamics 2 (reading outside school/home) LD3: Locational Dynamics 3 (reading at home) DD: Durational Dynamics FD1: Frequency Dynamics 1 (regularity of reading at school) FD2: Frequency Dynamics 2 (periodicity of reading at school) FD3: Frequency Dynamics 3 (regularity of reading outside school/home) FD4: Frequency Dynamics 4 (periodicity of reading outside school/home) FD5: Frequency Dynamics 5 (regularity of reading at home) FD6: Frequency Dynamics 6 (periodicity of reading at home) ID: Interventional Dynamics

\section{Supplementary Files}

This is a list of supplementary files associated with this preprint. Click to download.

- Plate1.png

- Plate2.png

- Plate3.png 